\title{
Contraction anisocoria: nasal versus temporal illumination
}

\author{
SHIRLEY A. SMITH AND S. E. SMITH \\ Department of Pharmacology, St Thomas's Hospital Medical School, London SEI 7EH
}

SUmmary The size of the pupillary reflex responses to flashes of light from 2 sources, positioned on each side of the visual axis, was measured in both eyes of 20 healthy subjects. When the nasal retina of one eye was illuminated, the direct reaction of that eye exceeded the consensual reaction of the other eye by a mean of $6.1 \%$ of reflex amplitude, whereas illumination of the temporal retina gave equal reflex responses.

Earlier work established that when one eye alone was stimulated with a flash of light the pupillary reflex amplitude in that eye exceeded the consensual reaction of the other eye. ${ }^{1}$ Although the magnitude of this contraction anisocoria was small (mean value $0.075 \mathrm{~mm}$ or $6.1 \%$ of reflex amplitude) it was found commonly in normal subjects, in contrast to the findings of other authors. ${ }^{23}$ The position of the light source used by Smith et al. ${ }^{1}$ was such that only the nasal retina was illuminated, whereas other workers used larger centrally placed light sources giving general retinal illumination. The present study was designed to test whether stimulation of the temporal retina results in the same degree of contraction anisocoria.

\section{Materials and methods}

Twenty healthy subjects of both sexes, mean age 28 years (range 19-49 years), who had no history of eye disease volunteered for the study. Vertical pupillary diameters were measured with a binocular infrared sensitive television pupillometer as described previously. ${ }^{1}$

Light reflexes were elicited by light flashes of $500 \mathrm{~ms}$ duration from 2 light sources (Sylvania $2 \mathrm{~W}$ tungsten arc lamps) positioned on either side of the visual axis of one eye and in the same horizontal plane. Both conical light beams were focused to a diameter of $1.8 \mathrm{~mm}$ in the plane of the pupil. One formed a mean angle of incidence of $6^{\circ} 30^{\prime}$ to the visual axis to illuminate the nasal retina $2^{\circ} 20^{\prime}$ to $10^{\circ} 40^{\prime}$ from the macula, that is, most of the area

Correspondence to Dr Shirley A. Smith, Department of Pharmacology, St Thomas's Hospital Medical School, London SE1 7EH.
Table 1 Mean contraction anisocoria in 40 eyes on nasal versus temporal retinal stimulation

\begin{tabular}{|c|c|c|c|c|c|c|}
\hline \multirow{2}{*}{$\begin{array}{l}\text { Retinal } \\
\text { stimulation }\end{array}$} & \multicolumn{3}{|c|}{$\begin{array}{l}\text { Direct minus consensual } \\
\text { reflex amplitude }(\mathrm{mm})\end{array}$} & \multicolumn{3}{|c|}{$\begin{array}{l}\text { Percentage of averaged } \\
\text { reflex amplitude }\end{array}$} \\
\hline & Mean & $S E M$ & $P$ & Mean & $S E M$ & $P$ \\
\hline Nasal & 0.08 & 0.02 & $<0.001$ & $6 \cdot 1$ & $1 \cdot 5$ & $<0.001$ \\
\hline $\begin{array}{l}\text { Nasal }+ \\
\text { temporal }\end{array}$ & 0.04 & 0.02 & $<0.05$ & $2 \cdot 5$ & $1 \cdot 1$ & $<0.05$ \\
\hline Temporal & 0.02 & 0.02 & NS & $1 \cdot 6$ & $1 \cdot 1$ & NS \\
\hline
\end{tabular}

NS = not significant.

between the macula and the blind spot. The other formed a mean angle of $14^{\circ} 30^{\prime}$ to the visual axis to illuminate the temporal retina $10^{\circ} 20^{\prime}$ to $18^{\circ} 40^{\prime}$ from the macula. The light intensities of each source were individually attenuated with Wratten neutral density filters to give submaximal and approximately equal pupillary reflex responses within the range 1.0 to $2 \cdot 0 \mathrm{~mm}$.

Flashes of light from either or both sources were directed at one eye every $8 \mathrm{~s}$ to give the following sequence of retinal stimulation: nasal and temporal together, nasal, then temporal. After one eye had received this sequence 3 times the experiment was repeated on the other eye. The resulting triplicate measurements of reflex amplitude for each of the 3 types of retinal stimulation were averaged.

\section{Results}

The occurrence of contraction anisocoria was found to depend on the position of the light upon the retina (Table 1). The difference between the direct and consensual reflex amplitude was greatest when the nasal retina alone was stimulated. The mean 
contraction anisocoria was $6 \cdot 1 \%$ of mean reflex amplitude on nasal stimulation and $2.5 \%$ when both lights were on together. The direct and consensual reflexes did not differ significantly when the temporal retina alone was illuminated.

\section{Discussion}

These results confirm that a small degree of contraction anisocoria results from flash illumination of the nasal retina of one eye. When the light source was on the other side of the visual axis to illuminate the temporal retina the light reflexes were of equal size. Stimulation of the nasal retina thus appears to provide a stronger stimulus to the pupil of the same eye than it does to that of the contralateral eye, though the difference is small (6.1\% of mean reflex amplitude).

The optic nerve fibres arising from the nasal retina cross in the chiasm and according to Kupfer et $a l^{4}$ the number of crossed fibres in the optic tract in man exceeds the number uncrossed by $6 \%$. However, for contraction anisocoria to have an anatomical basis it is necessary to postulate asymmetry in the subsequent decussation of fibres subserving pupillary function which occurs in the midbrain. There is no evidence for such an asymmetry, and at present no explanation can be offered for these results.

\section{References}

1 Smith SA, Ellis CJK, Smith SE. Inequality of the direct and consensual light reflexes in normal subjects. $B r J$ Ophthalmol 1979; 63: 523-7.

2 Jones IS. Anisocoria: attempted induction by unilateral illumination. Arch Ophthalmol 1949; 42: 249-53.

3 Lowen itein O, Loewenfeld IE. The pupil. In: Davson H, ed. The Eye. New York: Academic Press, 1969: 255-337.

4 Kupfer C, Chumbley L, Downer J de C. Quantitative histology of optic nerve, optic tract and lateral geniculate nucleus of man. J Anat 1967; 101 : 393-401. 